\title{
Atypical shotgun injury: wide dispersion of pellets inappropriate to intermediate range of fire
}

\author{
Rohan Ruwanpura \\ Consultant Judicial Medical Officer, Teaching Hospital, Karapitiya, Galle. \\ e-mail address of the corresponding author,Dr.Rohan Ruwanpura:rohanr@sltnet.lk
}

\section{Introduction}

A firearm death is one of the frequent encounters of forensic practice in Sri Lanka, probably due to increased circulation of unauthorized firearms over the last two decades. Though majority firearm cases are organised homicides, suicidal and accidental deaths are also often heard. While Chinese built T 56 assault rifle being the commonest weapon used in organized homicides, factory made shotguns and their local modifications are prevailing in individual crimes in rural setup ${ }^{1}$. The assessment of the range of fire is one of the key medico-legal issues in distinguishing suicidal and accidental cases from homicidal gunfire. The features of entry wounds are always useful in determining the range of fire ${ }^{2}$. Here we present a case of homicidal shot gun injury with unusual external injury pattern.

\section{Case History}

A 35 year-old woman was killed by an unknown gunman at her residence. According to statement of the eye witness, she was shot by a man, at the range of about one and half meters, from front of the victim, with a gun which is approximately two times bigger than a pistol. Soon after the incident, she was admitted to Karapitiya Teaching Hospital and pronounced dead at the emergency treatment unit. A fibrous wad and two spherical metallic slugs were recovered from the scene.

\section{Autopsy}

There were six approximately oval shaped penetrating lacerations, ranging from $0.5 \mathrm{~cm}$ to 1.5 $\mathrm{cm}$ in diameter, on the left side of the face, placed around the left eye. The injury situated at the inner end of the left eye, contained two metallic slugs, which penetrated into the anterior cranial fossa, causing subdural haemorrhage and cerebral laceration. Other penetrating injuries contained one slug at the bottom of each track. An oval shaped abrasion, $2 \mathrm{~cm} \times 3 \mathrm{~cm}$ in size, was present at the inner end of the left eye brow (Figure 1). A fine gun powder tattooing was noted on front aspect of the face. No burning or blackening was present. X-ray examination confirmed the fractures of orbital roof and left maxillary bone. The radius of dispersion of the penetrating lacerations was $10 \mathrm{~cm}$ (4 inches). The cause of death is given as necessarily fatal craniocerebral injuries due to the discharge of a shot gun at intermediate range.

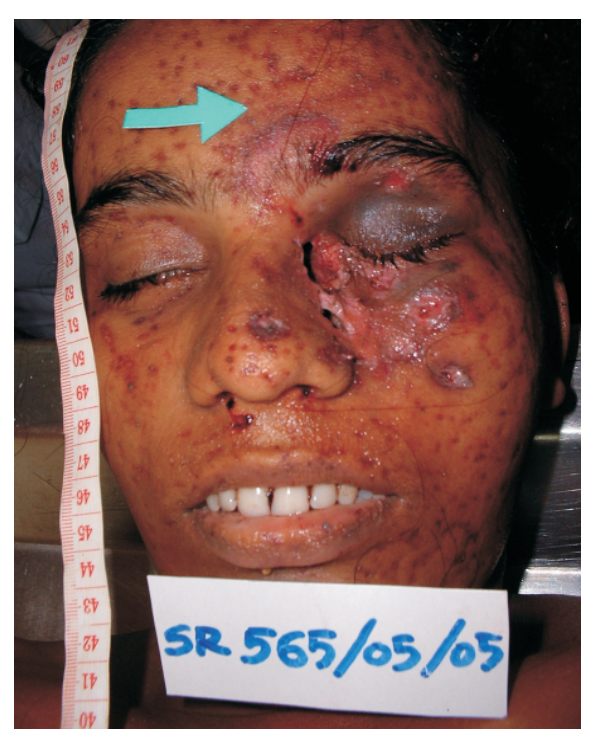

Figure 1 - Tattooing and penetrating lacerations on the face and abraded mark [arrowed] due to impact of a wad on forehead.

\section{Discussion}

The investigation of deaths due to fire arm injuries requires solving following medico-legal issues: the cause of death, possible period of survival after the injury and volitional activities, type of firearm, range 
of fire, direction of fire, number of shots and manner of death ${ }^{3}$. It is up to the prosecution to constitute reliable evidence in proof of the above requirements as any reasonable doubts raised by the defence regarding these issues invariably lead to acquittal of the accused person.

The autopsy findings of this case revealed that the death was due to direct cranio-cerebral injuries caused by pellets of a shot gun. The construction of shot gun ammunition greatly varies upon the manufacturer, and may contain one to nine large led spherical slugs or several hundreds of small metallic pellets. The metallic slugs and fibrous wad found in this case are typical of factory made SG type cartridges used in 12 bore standard shot gun, which carries nine slugs (metallic spheres) ${ }^{4}$. The type of the ammunition was further confirmed with police experts. The location and tract of injuries indicated that the victim had been fired from front, at a horizontal plane, which is in keeping with the circumstantial evidence.

The range of fire is one of the vital parameters in distinguishing suicidal deaths from homicides ${ }^{5}$. The range of fire in shot gun assault is determined by expression of effects of the fire such as burning around the entry, blackening due to soot, gun powder tattooing and wad marks which are present only within the range of about one meter ${ }^{6}$. Beyond that, the range is calculated by degree of dispersion of pellets or slugs ${ }^{7}$. The presence of gun powder tattooing and wad abrasion on the forehead of the victim indicated that the maximum possible range of fire must be up to two meters, as revealed in the circumstances. However, there had been a significant incompatibility of the range with the degree of dispersion of pellets (slugs). In a case of fire with a standard factory made 12 bore shot gun, the distance between muscle end of the gun and the victim should be around five meters for it to produce six separate entry holes dispersed over the area of about $10 \mathrm{~cm}$ (4 inches) in radius. In our experience, abnormally wider dispersion of shot gun pellets occurs when fired with a defective cartridge, through other objects like a glass plate or most likely when a length of the barrel is sawed off ${ }^{8}$. A sawn-off shotgun (U.K., Australia, New Zealand) also known as a sawed-off shotgun (U.S.) and a short-barreled shotgun (or SBS) is a type of shotgun with a shorter gun barrel and often a shorter or deleted stock, compared to a standard shotgun. The distal part of the barrel of a shot gun is usually choked to enhance the destructive range of fire by keeping bunch of bullets together. Hence, the removal of distal portion of the barrel causes a wider spread within a limited range, but it has about the same destructive power'. Its reduced size makes it easier to maneuver and conceal. This type of modified shot guns are often seen in Sri Lanka and known as a "Galkatas"10 (Figure 2).

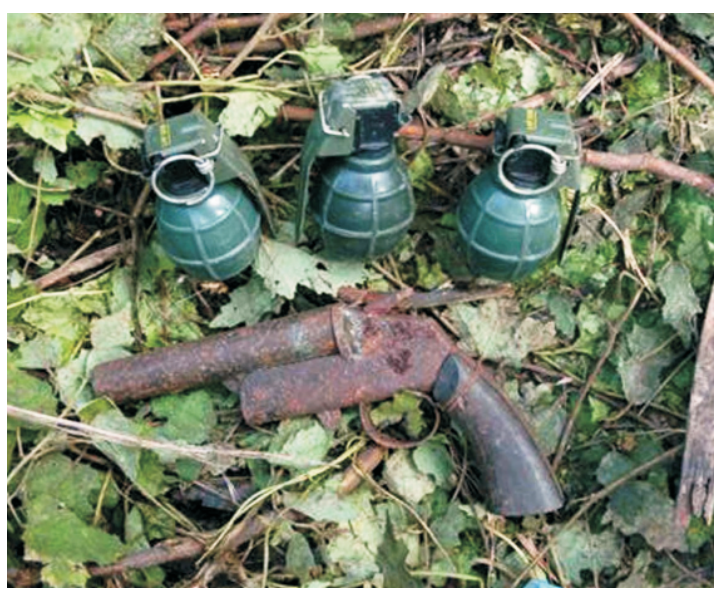

Figure 2 - A locally made short barrelled shot gun and factory made hand grenades recovered by the police from jungle hideout of an assailant.

In conclusion, the cause of death has been given as necessarily fatal injuries to the head due to the discharge of a short barreled shot gun, at intermediate range. This case highlights the value of scientific explanation for discrepancies between the injury patterns and characteristics of the weapon/ammunition in order to maintain criminal charges against the assailants at the court of law.

\section{Conflict of interest:}

Declared none.

\section{Acknowledgements}

Author acknowledges Drs. Mahinda Hettiarachchi, J. Warushenndi and Scene of Crime Officer, Galle Police S. Weerasinghe for their contribution in preparation of this paper. 


\section{References}

1. Available at - http://www.dailynews.1k/2005/07/06 /news13.htm. Date Accessed 21 June 2008.

2. Perdekamp MG, Bohnert M, Braunwarth R, Pollak S. Confusing injury findings in a suicidal gunshot fired to the chest from a carbine with a sawed-off barrel. Archives of criminology, Jan-Feb 2006; 217(1-2): 10-9.

3. Dodd MJ. Terminal Ballistics: A text and atlas of gunshot wounds. CRC press, New York, 2005; 91-4.

4. Available at - http://www.experiencefestival.com/a/ Shotgun_-_Ammunition/id/599502. Date accessed 12 July 2008.

5. Aydin B, Schulz F, Ottens R, Püschel K, Tsokos M. Fatal chest injury from a shotgun slug: homicide, accident or suicide? Arch Kriminol, Mar-Apr 2007; 219(3-4): 89-97.

6. Di Mao VJM. Gunshot wounds, Second edition, CRC Press, New York. 1999; 231-20.
7. De Georgio F, Rainio J. Two entrances, one exit-an atypical shot gun injury: a case report. Med Sci Law 2007 Oct; 47(4): 353-6.

8. Perdekamp MG, Vennemann B, Kneubuehl BP, Uhl M, Treier M, Braunwarth R, Pollak S. Effect of shortening the barrel in contact shots from rifles and shotguns. International Journal of legal medicine 2008 Jan; 122(1): 81-5.

9. Available at - http://en.wikipedia.org/wiki/Sawedoff_shotgun. Date accessed 16 January 2008.

10. Available at - http://en.wikipedia.org/wiki/Galkatas. Date Accessed June 2008. 